\title{
RISK FACTORS OF STUNTING IN CHILDREN UNDER FIVE YEARS OF AGE: A SYSTEMATIC REVIEW
}

\author{
Melly Nirma Syahriani, Ismarwati \\ Master Program of Midwifery, Health Sciences Department, \\ Universitas 'Aisyiyah Yogyakarta
}

\begin{abstract}
Background: Stunting, a chronic malnutrition, remains a serious global health concern. In 2019, UNICEF announced that 21.3\% of children under five years of age were stunted. This study aimed to analyze the factors associated with stunting to complement the evidence for stunting ongoing efforts.

Subjects and Method: A systematic review was conducted by searching from Science Direct, Wiley, EBSCO, and PubMed databases. The studies were synthesized by PEOS (Population, Exposure, Objective, and Study design), then appraised by Joanna Briggs Institute Critical Appraisal tools. The keywords were (((determinant) OR (causal factor) OR (risk factor)) AND (stunting)) AND ((toddler) OR (child)) OR (fives)) OR (Baby under five years old)). The inclusion criteria were English-language and primary studied full-text articles published in peerreviewed journals between 2009 and 2019. The exclusion criteria were opinion papers and review articles.

Results: The prevalence of stunted children under five was $21.9 \%$ globally. A total of selected eleven articles examined the causes of stunting in Low Middle-Income Countries (LMIC). Nine articles stated that gender and socio-economic factors associated with stunting. Six articles discussed the relationship between maternal age and stunting. Four articles revealed that maternal education level was one of the determinants of stunting. Two articles stated that nutritional status is strongly related to stunting. One article connected overweight as a contributing factor to stunting.

Conclusion: Stunting in Low Middle-Income Countries (LMIC) is associated with age, gender, socio-economy, maternal education level, nutritional status, and overweight children.
\end{abstract}

Keywords: stunting, children under five years, risk factor

\section{Correspondence:}

Melly Nirma Syahriani. Master Program of Midwifery, Universitas 'Aisyiyah Yogyakarta. Jl. Siliwangi (Ringroad Barat) No. 63, Nogotirto, Gamping, Sleman, Yogyakarta, 55292. Email: mellynirmas4@gmail.com. Mobile: +62895392131591. 